
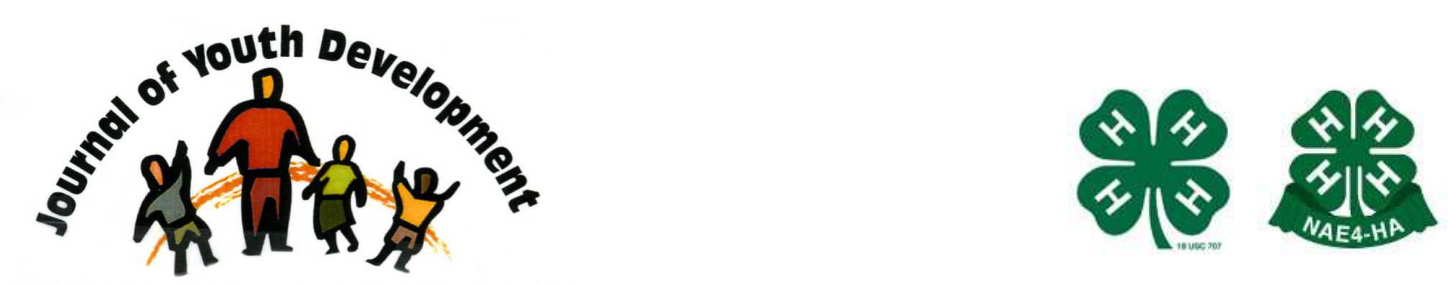

Bridging Research \& Practice

\title{
Bully Prevention: Creating Safe and Inclusive Environments for Youth
}

\author{
Kimberly Allen \\ 4-H Youth Development and Family and Consumer Sciences \\ North Carolina State University \\ Raleigh, NC \\ Kimberly allen@ncsu.edu \\ Robin Roper \\ 4-H Youth Development and Family and Consumer Sciences \\ North Carolina State University \\ Raleigh, NC \\ Robin Roper@ncsu.edu \\ Cara Lewis \\ 4-H Youth Development and Family and Consumer Sciences \\ North Carolina State University \\ Raleigh, NC \\ Cara lewis@ncsu.edu
}




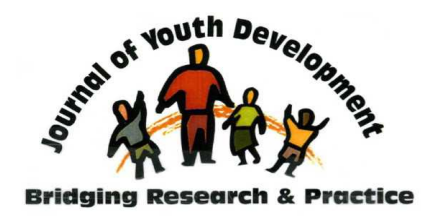

Volume 7, Number 3, Fall 2012

\section{JOURNAL OF YOUTH DEVELOPMENT \\ bridging research and practice}

\title{
Bully Prevention: Creating Safe and Inclusive Environments for Youth
}

\author{
Kimberly Allen, Robin Roper and Cara Lewis \\ North Carolina State University
}

\begin{abstract}
Bullying is a major issue facing youth of all ages, backgrounds, and walks of life. In fact, $30 \%$ of youth report experiencing bullying on a monthly basis (Nansel, Overpeck, Pilla, Ruan, Simons-Murton \& Scheidt, 2001). As a consequence, these youth are at much greater risk for a host of mental and physical problems (Ttofi \& Farrington, 2008). Parents, teachers, educators and youth advocates all agree that this issue merits time and attention, yet many professionals are at a loss for understanding the issue or what resources might be most effective with their young audience. With the increased rates of bullying behaviors and growing research about effective prevention and intervention strategies, youth development professionals need guidance for creating and sustaining bully prevention efforts. The purpose of this article is to highlight the growing research on bully prevention and provide information for practitioners working to create safe and inclusive environments for youth.
\end{abstract}

\section{Introduction}

Within the past two decades, the amount of empirical information on bullying has dramatically increased, and youth professionals have more information and better resources than ever available to build effective bully prevention programs. There is now a great amount of information about the rates of bullying behaviors, the impact of bullying on youth and the necessary components of effective bully prevention programs; so much so that professionals might feel overwhelmed by where to start bully prevention efforts. This paper seeks to synthesize findings from empirical studies on effective bully prevention efforts in order to help youth professionals better understand how to create safe and fully inclusive environments within the organizations they serve. 


\section{Prevalence of Bullying}

For the majority of youth today, bullying is a common part of life. Statistics vary, but as many as $70 \%$ of all youth report being impacted either directly or indirectly from bullying (Cantor, 2005). In fact, $48 \%$ of elementary and $47 \%$ of middle school youth report having been bullied in the last month (Bradshaw \& Waasdorp, 2009; Nansel et al., 2001). The rate of bullying behaviors has increased over the past decade (Swearer, 2011), and two-thirds of youth reported that they had witnessed bullying in the past month (Bradshaw \& Waasdorp, 2009). Both boys and girls tend to engage in and be targets of bullying behaviors; nearly $50 \%$ of boys and $40 \%$ of girls report having been the target of bullying behavior (Nansel, et al., 2001). Although bullying rates for gender are fairly equal, the types of bullying behaviors vary greatly by gender; boys often engage in physical violence while girls use more covert forms such as gossip, harassment and rumor spreading (Borg, 1998) and cyberbullying (Hinduja \& Patchin, 2009).

Findings from the 2011 National Education Association's Nationwide Study of Bullying (ESP) show that bullying takes many forms, with school staff reporting that verbal (59\%), social/relational (50\%), and physical (39\%) forms were of greater concern in their school than was cyberbullying (17\%) (Bradshaw, Wassdorp, O’Brennan \& Gulemetova, 2011). This report supports others studies that have shown that name-calling and teasing tend to be the most common forms of bullying, followed by physical violence and threats (Beaty \& Alexeyev, 2008; Bradshaw \& Waasdorp, 2009). Bullying tends to occur in places where children congregate with little or no supervision, such as the school playground, hallways, classrooms, bathrooms and the school cafeteria (Olweus, 1993).

Children who have trouble fitting in were most at risk for being the target of bullying behaviors. Specially, bullying was often targeted based on a student's weight $(23 \%)$, gender $(20 \%)$, perceived sexual orientation (18\%), or disability (12\%) (Bradshaw, Wassdorp, O’Brennan \& Gulemetova, 2011). Youth with disabilities or special educational needs (Whitney, Nabuzoka, \& Smith, 1992) and those from sexual minority groups (Kosciw, Greytak, Diaz \& Bartkiewicz, 2010) tend to be the most vulnerable for bullying.

\section{Impact of Bullying on Youth}

Bullying affects youth of all ages, backgrounds, and walks of life. Although bullying can start as early as preschool, it peaks during late elementary and middle school and declines through high school grades (Bradshaw \& Waasdorp, 2009). Bullying behaviors result in a barrage of negative effects for youth; these youth often feel upset, hurt, and scared. These experiences then impact the mental and physical health of youth.

Youth who are bullied tend to be more depressed, have lower self-esteem, have more health issues and miss more school than other children (Olweus, 1993; Rigby \& Cox, 1996). Physically, youth who experience bullying have more trouble sleeping, and suffer from headaches and abdominal pain (Fekkes, Pijpers \& Verloove-Vanhorick, 2004). These youth are fearful and often suffer in silence when adults in their lives fail to help. In turn, youth who are bullied tend to miss school-an estimated 160,000 students miss school at least once each year due to the fear of being bullied (Lee, 1993) and in general, they don't like school and get lower grades (Bradshaw, O'Brennan \& Sawyer, 2008). Youth who are targeted by bullies tend to be fearful and often suffer in silence when adults in their lives fail to help. In turn, these youth tend to suffer from mental health issues (Swearer, 2011). 
There are two subsets of youth targeted for bullying: passive victims and bully-victims (Olweus, 1993). Passive victims tend to be insecure and often isolated from other youth whereas bullyvictims may have similar traits as passive victims, but they also tend to be impulsive and much more likely to fight back (Olweus, 1993). Bully-victim youth are also more likely to engage in bullying behaviors with other youth.

Problems lie not only for those that are targets of bullying behaviors, but also for observers and for the youth who bully others. Youth who bully others tend to exhibit a host of risk behaviors, including alcohol consumption, smoking, and other anti-social behaviors (Gulemetova, Drury \& Bradshaw, 2011). Although there is no single cause of bullying, these youth tend be more impulsive and view violence in a positive light (Olweus, 1993b). Youth who exhibit bully behaviors tend to come from families who offer little emotional support, a lack of clear limits, limited supervision and a lack of warmth (Olweus, Limber \& Mihalic, 1999). Additional risk factors include being a part of a peer group who has a favorable view of violence and who bully others (Olweus, Limber \& Mihalic, 1999). These youth report having little or no adult support, and tend to have a lack adult supervision. Researchers have also found a link between bullying behaviors in youth and later criminal actions (Olweus, 1993).

Most incidences of bullying occur in the presence of other youth and sometimes in the presence of other adults. One study showed that $85 \%$ of all bullying behaviors occurred in front of others (Craig \& Pepler, 1997). Youth who witness bullying tend to also be fearful, and have no clear ideas of how to intervene. As a result, they often have feelings of guilt or even participate in the bullying behaviors (Salmivalli, Voeten \& Poskiparta, 2011). Bystanders tend to watch and do not intervene, and sometimes even the adults do not intervene. $54 \%$ of high school students and $43 \%$ of middle school students say they have seen adults watch the bullying occur and the adults have done nothing about it; $66 \%$ of high school and $58 \%$ of middle school students do not think adults do enough to stop bullying (Bradshaw, Sawyer \& O'Brennan, 2007).

\section{Empowering Youth Professionals with Training}

Although at one time commonly accepted, bullying is no longer considered to be a right of passage; it is clear youth need help from the adults in their lives to navigate the world of bullying. Many youth professionals, parents and community members are working together to create inclusive communities, but there is a gap in education, skills and knowledge of how to deal with bullying behaviors. Youth professionals who receive bully prevention training are more likely to intervene and feel safer in their environment than professionals without training (Bradshaw, et al., 2007). Only $27 \%$ of staff and $42 \%$ of teachers in a national survey reported ever being involved in bully prevention efforts and more than half stated a need for additional training in how to intervene (Bradshaw, et al., 2011).

Youth professionals want to help with bully prevention and intervention efforts, but report feeling unprepared to do so (Bradshaw, Wassdorp, O'Brennan \& Gulemetova, 2011). There is a good deal of information about bully prevention programs, but there is a deficit in empiricallybased recommendations for youth professionals and a deficit in getting resources to youth professionals so that they can be a part of the prevention process. 


\section{A Review of Current Research}

In an effort to help fill this gap, a systematic review of bully prevention programs was conducted in order to create a list of recommended practices that can aid youth professionals in their efforts to create and implement bully prevention programs for their organization.

\section{Methodology}

This systematic review investigated the current research describing core components of effective bully prevention programs. A systematic review is a rigorous method of reviewing literature in an effort to produce an evidence base for interventions and practice (Whiting, 2009). The review included studies that examined the association between bullying behaviors and bully prevention. Article searches were completed through Summon database using search terms related to bully prevention, intervention, and safe youth environments. All articles that fit the search terms were then screened and sorted as relevant or irrelevant. Because bullying is currently a popular topic of instruction and information, the authors also conducted a Google search for popular press and educational resources to be reviewed. Articles that described essential elements of bully prevention programs as well as those describing implications for practitioners were selected for review.

\section{Results}

The research conducted showed that, overall, anti-bullying programs are effective in reducing bullying behaviors and that within bullying research; there is strong evidence of best practices to use when designing a bully prevention program. In total, the systematic review yielded five core prevention and intervention components recommended to be included in comprehensive bully prevention programs. Those core components are:

1. Community-based, multi-environment prevention activities

2. Multi-tiered prevention approaches utilizing positive behavior supports

3. Involving parents and families

4. Integrating and sustaining proven prevention efforts

5. Emphasizing vulnerable audiences

Additionally, 11 specific actions recommended for bully preventions were identified and are described below.

\section{Community-based, multi-environment prevention activities}

Consistent with the social-ecological framework, youth programs should address the social environment and the broader culture and climate of bullying (Bradshaw \& Waasdorp, 2009). Changing the climate in which bullying takes place is not easy; it requires the inclusion of a full range of systems, from the student to the society. Research documents the importance of community-wide prevention efforts that provide positive behavior support, establish a common set of expectations for positive behavior across all contexts, and involve more than school staff and parents in prevention activities (Ross, Horner, \& Stiller, 2009).

Furthermore, supervision - especially in areas that typically have limited supervision such as hallways and playgrounds and clear anti-bullying policies are essential elements of a successful bully prevention program (Olweus, 1993). Involving youth by conducting a needs assessment of their perceptions of problems and solutions is also key, and collecting data from anonymous 
student surveys can inform the supervision and intervention process (Bradshaw \& Waasdorp, 2009). These data can identify potential areas of need for intensive training for all staff, youth and community partners, including parents. Data are also critical for monitoring progress toward the goal of reducing bullying (Olweus, 1993). Furthermore, training specifically designed to educate adults in all youth development roles is recommended.

\section{Multi-tiered prevention approaches utilizing positive behavior supports}

Not all students respond to prevention efforts in the same way, so utilizing an approach that can target students at different levels is recommended. A common approach to the prevention of bullying and other emotional and behavioral problems is the three-tiered public health model. This model has three levels of support; the primary (full organization), secondary (small groups) and tertiary (individual) levels (Sugai \& Horner, 2009). The desired result is a universal system of support that impacts all students within a defined youth setting.

At the primary level, organizational interventions are implemented targeting ALL students. Most organization-wide programs exist at the primary level, reaching most, if not all students. Research highlights the importance of providing class time to discuss bullying (Olweus, 1993) and the use of lessons to foster skills and competencies, effective communication, and strategies for responding to bullying (Farrington \& Ttofi, 2010). These activities can have a positive impact on academic and other behavioral outcomes (Durlak, Weissberg, Dymnicki, Taylor \& Schellinger, 2011; Sugai, Horner, 2009;). Effective environment management is also critical, as well-managed youth areas, including classroom and work environments, are rated as having a more favorable climate, being safer, more supportive, and having lower rates of bullying (Koth, Bradshaw \& Leaf, 2008).

Some youth, however, need more intensive prevention or intervention. At the secondary level, targeted interventions are implemented in small groups for those students who are "nonresponders" to the universal strategies. These youth receive selective interventions that target specific skills and may include social skills training for small groups of children at risk for becoming involved in bullying. The focus of these small groups needs to include strength-based, positive attention and regular feedback (Sugai \& Horner, 2009).

At the tertiary level, intensive interventions are implemented, targeting individual students that need specialized support. A tertiary intervention may include more intensive supports and programs tailored to meet the needs of students and families of students identified as exhibiting bully behaviors or targeted students (Espelage \& Swearer, 2008; Ross, Horner, \& Stiller, 2009). Perpetrators and targets of bullying should not be brought together in these circumstances; the best approach is to deal separately with these students. The power differential is so great that bringing both parties together could yield even worse results for the youth that had been a target (Limber \& Snyder, 2006). These interventions should be person-centered and are best when they connect the youth with additional community support, including familial support (Sugai \& Horner, 2009).

\section{Involving parents and families}

Families play a critical role in bullying prevention by providing emotional support to promote disclosure of bullying incidents and by fostering coping skills in their children. A parent's response to bullying greatly influences a youth's experience of bullying (Mishna \& Alaggia, 2005). Youth, in particular older youth, may be hesitant to talk with their parents about their bullying experiences (Atlas \& Pepler, 1998), thus it is important for parents to be educated on the topic so they know both what to look for and what to do. Parents need training in how to talk with their children about bullying, how to communicate their concerns about bullying to the 
school, and how to get actively involved in school-based bullying prevention efforts (Sawyer, Mishna, Pepler \& Wiener, 2011). Informational nights that include materials that help parents understand how to help their youth are encouraged. There are also important bullying prevention activities that can occur at the community level, such as awareness or social marketing campaigns that encourage all youth and adults to intervene when they see bullying and to become actively involved in school and community-based prevention activities (HRSA, n.d.; Olweus, 1993).

\section{Integrating and sustaining proven prevention efforts}

Research by Gottfredson and Gottfredson (2001) indicates that, on average, schools are using about 14 different strategies or programs to prevent violence and promote a safe learning environment. This can often be overwhelming for school staff to execute well, thereby leading to poor implementation fidelity. Therefore, schools are encouraged to integrate their prevention efforts so that there is a seamless system of support that is coordinated, monitored for high fidelity implementation, and includes all staff across all school contexts. Instead of adopting a different program to combat each new problem that emerges, it is recommended that schools develop a consistent and long-term prevention plan that addresses multiple student concerns through a set of well-integrated programs and services (HRSA, n.d.). Such efforts would address multiple competencies and skills in order to prevent bullying, and help students cope and respond appropriately when bullying does occur. Furthermore, utilizing evidence-based curricula and programs is recommended. Programs that have rigorous research supporting their effectiveness improves the likelihood that the program will be successful.

\section{Emphasizing vulnerable audiences}

In conducting the review, it was noted that the subset of youth at highest risk for being targeted for bullying behaviors included lesbian, gay, bi-sexual, transgendered \& questioning (LGBTQ), religious minority, and youth with disabilities. Most bully prevention programs, even the most comprehensive and community-minded initiatives, do not specifically address the changing demographics of communities and fail to incorporate factors such as race, disability, sexual orientation and religious minorities. In a review of bully prevention curricula, it was noted that there was a major gap of training resources specifically geared to these vulnerable youth (Allen, Lewis, Roper \& Vandehoe, in press). However, adults who work with youth report they do not know how nor do they feel comfortable directly addressing bullying incidences that are directed at targeted groups (Bradshaw, et al., 2011). Programs need to include skills based training for youth and adults specifically targeting vulnerable groups.

In addition to the five core components of effective bully prevention programs, there are additional overarching components and specific actions recommended for bully prevention programs.

- Whole-organization anti-bullying policy - Creating and maintaining a formal antibullying policy for the entire organization or school.

- Organization-wide meetings open to the public - In many programs, these meetings are organized after the pre-test data collection and aimed to inform students, parents and the community about the extent of bullying behavior and anticipated procedures in their environment.

- Cooperative group work - Communication and cooperation among varying stakeholders, including educators, parents, students, administration, and support staff in working with bully prevention efforts. 
- Environment management - Environment or classroom management strategies and techniques in detecting and dealing with bullying behavior. The educator needs to enforce organizational policy and procedures and establish an accepting, bully free environment.

- Free time or playground supervision - Bullying often occurs at times with minimum supervision; it is important to have adults that are trained in recognizing signs of bully behaviors to monitor youth in such settings.

- Mutual agreements and rules- Rules can be the result of cooperative group work between the youth and adults, usually after some extent of exposure of the students to the philosophy or messages of the anti-bullying program. Agreements should be displayed in a distinctive place in the program meeting room or classroom.

- Consistent discipline - Clear and consistent application of positive discipline and consequences.

- Working with bullies and targets - Separate individualized work with targets and perpetrators, never together at the same time. In most programs, this service is offered by professionals, such as administrators, counselors or psychologists in collaboration with other youth professionals.

- Curriculum materials - Utilizing holistic, evidence-based prevention curricula. For a list, see Allen, Lewis, Roper, \& Varnadoe (2012)

\section{Implications}

Youth professionals know that children do not live in a vacuum; they are a part of an larger ecological system that includes their family and school (environment) their community (culture) and their society (climate). Youth development programs have historically utilized the theory of ecology as a foundation for program development, and bully prevention programs are no exception. Research shows that best results occur when the whole society comes together to build an inclusive and safe climate (Swearer, Espelage, Vaillancourt \& Hymel, 2010). Youth professionals directly impact the child's environment, and can work in the community and society to change the culture and climate.

One of the most effective ways to decrease and prevent bullying in any organization is to improve connections among all people in the community. When all three systems work together to create a safe and inclusive climate, youth are much more likely to feel safe and be successful.

\section{Community Connection is Critical}

All members of the youth development community play a role--this includes community partners, all staff members, volunteers, parents and all students, as each person is likely to be an observer or bystander when bullying occurs. But in order for these adults to engage, they need training on policies and proper procedures. A study of School-Wide Positive Behavior Supports found that staff who experience a greater sense of connectedness report a greater willingness to intervene in bullying situations (Ross, Horner \& Stiller, 2009). There is also a link between how or if youth professionals handle bullying situations and their attitudes toward intervention (Bradshaw, Sawyer \& O'Brennan, 2007). Those who are not trained are less comfortable and thus less willing to get involved in a bullying incident. All youth professionals must know how to identify bullying behaviors and understand how to intervene, and then they must intervene. 
The most effective bullying prevention programs are comprehensive and are inclusive of a variety of stakeholders, including formal and informal education professionals, parents, youth, and other stakeholders. In a model program, for example, a community school district would conduct a needs assessment that includes data from youth, staff, parents and partners as well as an asset inventory to identify existing strengths for inclusion in prevention activities. School administration might then hold a public meeting to which youth, parents, school personnel, afterschool providers, extra-curricular partners, youth development community partners, and business partners are invited and at which information would be provided highlighting the results from the needs assessment and asset inventory. In addition, any existing or updated bullying prevention policies would be explained. From that meeting, a cooperative work group would be formed for training, sustainability and accountability.

Training is a critical piece of bullying prevention. Adults that do not have proper training report wanting to intervene, but on occasion do not as they feel they do not have the skills (Bradshaw et al., 2011) Youth serving organizations need to offer a series of trainings that would be open to all stakeholders. The training should be well researched and ideally evidence based (see Allen et al, 2012 for a list of evidence and research-based curriculum). The training should be skills based, and include information about how to intervene, proper procedures, positive behavior support, and specific information for dealing with targeting specific vulnerable populations. There should also be training for youth, which includes information for bystanders. Once implemented and trained, there should be additional support for students in tiers 2 and 3, both group based and individualized. Youth professionals should then consistently enforce the new policy and procedures and work with the students to create agreements for the behavior standards.

Finally, if bully incidences occur, staff, students and parents should intervene with consistency. Adults should stop any bullying behaviors immediately, separate the youth involved, then make sure everyone is safe (Stopbullying.gov, 2011). It is important to find out what happened, and determine if it is normal conflict, or bullying. School policies should identify the difference of normal conflict and bullying in order for objectivity to occur. From that point, staff would follow the school protocol and get both youth the help they need which should include emotional support to the target and the youth who bullies.

\section{Conclusion}

Gone are the days of "boys will be boys" and "kids will be kids." Bullying behaviors cause a host of problems, many of which are life long, for all parties involved. Youth that are engaging in or targets of aggressive behaviors do not do well, and rates of aggressive behaviors will not decrease without adult intervention. It is clear that bullying is a major issue and youth professionals must act on this issue. Creating a safer, more inclusive environment fits with models of positive youth development, and thus putting a system in place that helps youth feel safe and included is an essential part of youth development.

There are many roles to play in creating a safe and inclusive environment. Parents, educators, community members and youth need to all be a part of bullying prevention efforts. The results of this study show that there are five critical elements that are needed for creating a safe and inclusive environment for youth. First, youth serving organizations need to be comprehensive in their bullying prevention approach by including a large variety of stakeholders in prevention efforts. Youth, parents, staff and community partners all need to be a part of the solution. Second, approaches to prevention and intervention need to be targeted; one approach for the 
whole setting is a start, but there needs to be support and resources in place for those whom the organizational wide messaging does not affect.

Third, it is critical to involve families in every part of the prevention and intervention efforts. Fourth, youth professionals need to use proven practices. No need to reinvent the wheel; there are a great number of validated resources available to help organizations get bullying prevention programs started. Finally, youth organizations must include specific strategies and trainings that emphasize vulnerable audiences. GLBTQ, religious minority, and students with disabilities are the highest risk, so including these populations is critical for inclusivity. Together, communities can support youth and families by talking about bullying, and put in place a clear blueprint for creating a positive youth development environment.

\section{References}

Allen, K., Lewis, C., Roper, R., \& Varnadoe, C. (2012). Bullying prevention: A guide for youth professionals. A report written for the National 4-H Council and The National Institute of Food and Agriculture.

Allen, K., Roper, R., Lewis, C., \& Vandehoe, C. (in press). Creating a safe and inclusive community in youth environments: A guide to bully prevention programs. National 4-H Council.

Atlas, R.S., \& Pepler, D.J. (1998). Observations of bullying in the classroom. Journal of Educational Research, 92(2), 86-99.

Beaty, L.A., \& Alexeyev, E.B. (2008). The problem of school bullies: What the research tells us. Adolescence, 43(169). 1-10.

Borg, M.G. (1998). The emotional reactions of school bullies and their victims. Educational Psychology, 18, 433-435.

Bradshaw, C.P., \& Waasdorp, T.E. (2009). Measuring and changing a culture of bullying. School Psychology Review, 38(3), 356-361.

Bradshaw, C.P., Koth, C.W., Thornton, L.A., \& Leaf, P.J. (2009). Altering school climate through school-wide Positive Behavioral Interventions and Supports: Findings from a group-randomized effectiveness trial. Prevention Science, 10(2), 100-115.

Bradshaw, C.P., O’Brennan, L., \& Sawyer, A.L. (2008). Examining variation in attitudes toward aggressive retaliation and perceptions of safety among bullies, victims, and bully/victims.

Professional School Counseling, 12(1), 10-21.

Bradshaw, C.P., Sawyer, A.L., \& O’Brennan, L.M. (2007). Bullying and peer victimization at school: Perceptual differences between students and school staff. School Psychology Review, 36 (3), 361-382. 
Bradshaw, C.P., Waasdorp, T.E., O'Brennan, L.M., \& Gulemetova, M. (2011). Findings from the National Education Association's nationwide study of bullying: Teachers' and education support professionals' perspectives. National Education Association. Retrieved from:

http://www.nea.org/assets/img/content/Findings_from_NEAs_Nationwide_Study_of_Bullying.pd f.

Cantor, A.S. (2005). Bullying at school. Principal, 85(2), 42-45.

Craig, W., \& Pepler, D. (1997). Observations of bullying and victimization in the schoolyard. Canadian Journal of School Psychology, 2, 41-60.

Durlak, J.A., Weissberg, R.P., Dymnicki, A.B., Taylor, R.D., \& Schellinger, K.B. (2011). The impact of enhancing students' social and emotional learning: A meta-analysis of school-based universal interventions. Child Development.

Espelage, D.L., \& Swearer, S.M. (2008). Addressing research gaps in the intersection between homophobia and bullying. In D.L. Espelage, \& S.M. Swearer. (Eds.), Sexual Orientation, Homophobia, Bullying, and Psychological Adjustment During Adolescence [Special issue]. School Psychology Review, 37, 155-159.

Farrington, D.P., \& Ttofi, M.M. (2010). School-based programs to reduce bullying and victimization. Submitted to the U.S. Department of Justice for publication.

Fekkes, M., Pijepers, F.I., \& Verloove-Vanhorick, S.P. (2004). Bullying behavior and associations with psychosomatic complaints and depression in victims. Journal of Pediatrics, 144(1), 17-22.

Gottfredson, G.D., \& Gottfredson, D.C. (2001). Gang Problems and Gang Programs in a National Sample of Schools. Ellicott City, Maryland: Gottfredson Associates, Inc. Available online at http://www.gottfredson.com/gang.htm.

Gulemetova, M., Drury, D., \& Bradshaw, C.P. (2011). National education association bullying study. Colleagues. 6(2). Available at: http://scholarworks.gvsu.edu/colleagues/vol6/iss2/11)

Health Resources and Services Administration. (HRSA; n.d.a). Best practices in bullying prevention and intervention. Retrieved on December 15, 2010 from http://www.stopbullying.gov.

Hinduja, S., \& Patchin, J.W. (2009). Bullying beyond the Schoolyard: Preventing and Responding to Cyberbullying. Thousand Oaks, CA: Sage Publications

Kosciw, J.G., Greytak, E.A., Diaz, E.M., \& Bartkiewicz, M.J. (2010). The 2009 National School Climate Survey: The experiences of lesbian, gay, bisexual and transgender youth in our nation's schools. New York: GLSEN. Massachusetts Department of Education (2004). 2003 Youth Risk Behavior Survey Results. Malden, MA: Author.

Koth, C.W., Bradshaw, C.P., \& Leaf, P.J. (2008). Examining the relationship between classroomlevel factors and students' perception of school climate. Journal of Educational Psychology, 100, 96-104.

Lee, F. (1993). Disrespect rules. The New York Times Educational Suppl., p. 16. 
Limber, S., \& Snyder, M. (2006). What works-and doesn't work-in bullying prevention and intervention. The State Education Standard. 24-28.

Mishna, F., \& Alaggia, R. (2005). Weighing the risks: A child's decision to disclose peer victimization. Children \& Schools, 27(4). 217-227.

Nansal, T.R., Overpeck, M., Pilla, R.S., Raun, W.J., Simons-Morton, B., \& Scheidt, P. (2001). Bullying behaviors among U.S. youth-Prevalence and association with psychosocial adjustment. Journal of the American Medical Association, 285, 2094-2100.

Olweus, D. (1993). Bullying at school: What we know and what we can do. Oxford: Blackwell Publishers.

Olweus, D. (1993b). Victimization by peers: Antecendents and long-term outcomes. In K.H. Rubin \& J.B. Asendorf (Eds.), Social withdrawal, inhibition, and shyness. Hillsdale, NJ: Erlbaum.

Olweus., D., Limber, S., \& Mihalic, S. (1999). The bullying prevention program. Blueprints for violence prevention. Boulder, CO: Center for the study and prevention of violence.

Rigby, K., \& Cox, I.K. (1996). The contributions of bullying and low self-esteem to acts of delinquency among Australian teenagers. Personality and Individual Differences. 21(4), 609612.

Ross, S. Horner, R.H., \& Stiller, B. (2009). Bully prevention in Positive Behavior Support. Retrieved from: www.pbis.org.

Salmivalli, C., Voeten, M., \& Poskiparta, E. (2011). Bystanders matter: Associations between reinforcing, defending, and the frequency of bullying behavior in classrooms. Journal of Clinical Child \& Adolescent Psychology, 40(5), 668-676.

Sawyer, J., Mishna, F., Pepler, D. \& Wiener, J. (2011). The missing voice: Parent's perspectives of bullying. Children and Youth Services Review, 33(10) 1795-1803.

Stopbullying.gov. (2011). Respond to bullying. Retrieved from: http://www.stopbullying.gov/respond/index.html

Sugai, G., \& Horner, R.H. (2009). Responsiveness-to-intervention and school-wide positive behavior supports: Integration of multi-tiered approaches. Exceptionality, 17, 223-237.

Swearer, S.M. (2011). Risk Factors for and Outcomes of Bullying and Victimization. Educational Psychology Papers and Publications. Paper 132.

http://digitalcommons.unl.edu/edpsychpapers/132

Swearer, S.M., Espelage, D.L., Vaillancourt, T., \& Hymel, S. (2010). What can be done about school bullying? Linking research to educational practice. Educational Researcher, 1, 38-47.

Ttofi, M.M., \& Farrington, D.P. (2008). Bullying: Short-term and long-term effects, and the importance of Defiance Theory in explanation and prevention. Victims and Offenders, 3, 289312. 
Whiting, L. (2009). Systematic review protocols: An introduction. Nurse Researcher, 17 (1), 3443.

Whitney, I., Nabuzoka, D., \& Smith, P.K. (1992). Bullying in schools; Main-stream and special needs. Support for Learning, 7(1), 3-7.

(C) Copyright of Journal of Youth Development $\sim$ Bridging Research and Practice. Content may not be copied or emailed to multiple sites or posted to a listserv without copyright holder's express written permission. However, users may print, download or email articles for individual use. 